\title{
Severe Anemia and Thrombocytopenia in a Premature Associated with a Large Placental Chorioangioma
}

\author{
Hong Jiang, Yan Liu, Mengya Sun* \\ Qingdao University, Qingdao, China \\ Email: sunmengya616@163.com
}

Received 17 February 2015; accepted 10 March 2015; published 11 March 2015

Copyright (C) 2015 by authors and Scientific Research Publishing Inc.

This work is licensed under the Creative Commons Attribution International License (CC BY). http://creativecommons.org/licenses/by/4.0/

\section{(c) (i) Open Access}

\begin{abstract}
Chorioangioma is a tumor of vascular placental origin, the most frequent among primary placental non-trophoblastic tumors; however, it is found in about $1 \%$ of placental pathology case studies. Most of the chorioangiomas found are small, asymptomatic lesions that are only found postnatally after careful slicing of the placenta [1]. Larger tumors, particularly those measuring more than 4 $\mathrm{cm}$, are rarely seen in obstetric practice but are clinically significant. In this case report, we will show you the premature with large chorioangioma and we will tell the treatment we take to cure the baby successfully.
\end{abstract}

Keywords

Premature, Chorioangioma, Severe Anemia, Thrombocytopenia

\section{Case Report}

The mother was a 33-year-old yellow multipara with no significant antenatal history. There was no maternal fever and her complete blood count was normal. In the $24^{\text {th }}$ week, a large chorioangioma measuring $7.9 \times 5.5 \times$ $5.7 \mathrm{~cm}$ could be readily identical prenatally by sonography as a well-circumscribed, solid mass. She wanted to give birth to this baby till full term and accepted suggestion of taking examination regularly. In the $30+4$ gestational age, the mass enlarged much about $14.1 \times 9.7 \times 13.0 \mathrm{~cm}$ with generalized edema and hydropericardium of the foetus. Figures 1(a), Figures 1(b) show the foetus and the tumor. An emergency cesarean section was performed. The placenta weighs $1180 \mathrm{~g}$ and measures $20 \times 15 \times 3 \mathrm{~cm}$. A well-circumscribed soft tissue mass bulging out of the placenta was seen measuring $15 \times 10 \times 13 \mathrm{~cm}$. There was no sign of malignancy and the diagnosis after pathology was chorioangioma. Figures 1(c), Figures 1(d) show the microscopic picture of the chorioan${ }^{*}$ Corresponding author. 


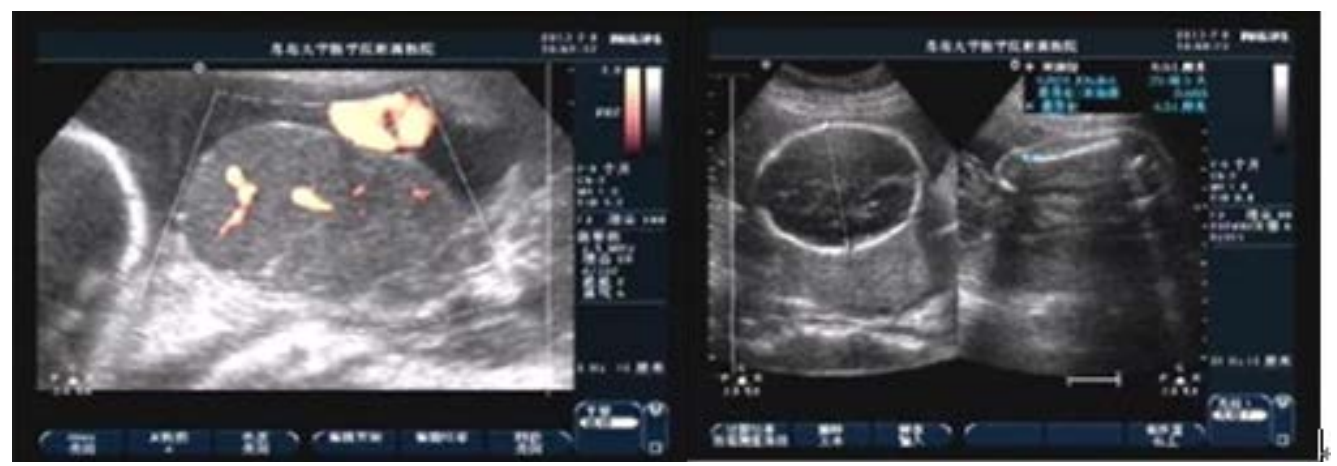

(a)

(b)

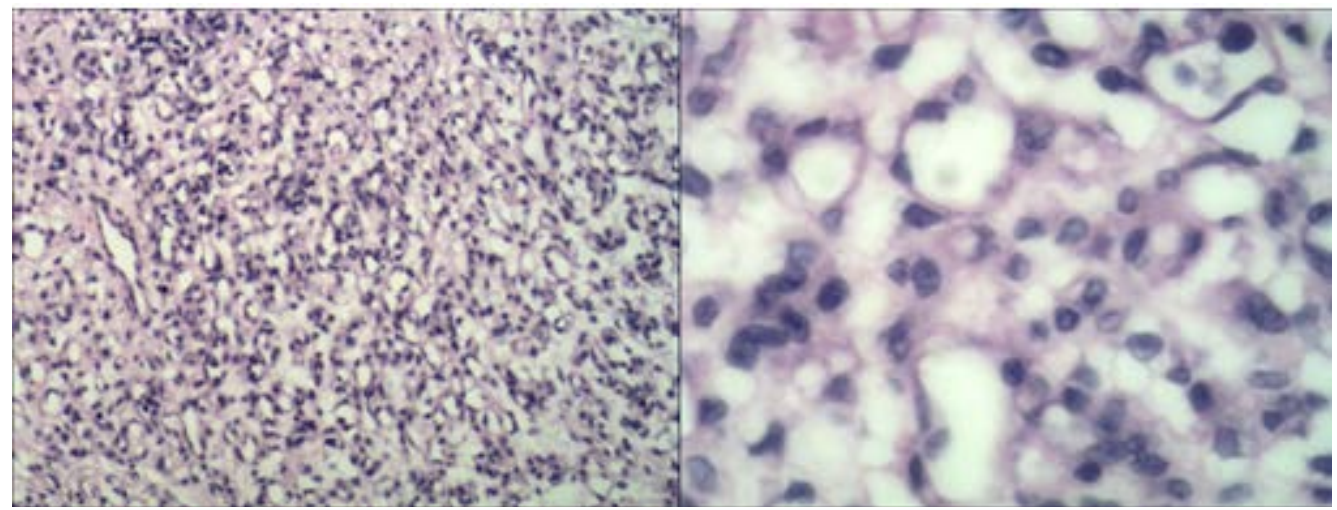

(c)

(d)

Figure 1. (a) Sonography shows fetal right atrium, ventricle enlarged, and liquid dark area could be seen within the pericardium, depth of about $0.34 \mathrm{~cm}$. Cephalic subcutaneous tissue thicken, about $0.79 \mathrm{~cm}$. Fetal surface of placenta detected a well-circumscribed hypoechoic mass, measuring $14.1 \times 9.7 \times 13.0$ $\mathrm{cm}$ on the right side in which the internal echo was uneven and many small pieces of high echo could be seen; (b) (CDFI) Abundant blood flow signal was observed in the chorioangioma; (c) and (d) Tumor consisted of excessive proliferated capillaries, vascular pericytes cells and interstitial collagen.

gioma.

The female premature neonate was $1.94 \mathrm{~kg}$ of birth weight (normal 2500 - $3999 \mathrm{~g}$ ). There was severe asphyxia at birth, Apgar score at 1 minute being 6/10 (the respiration was deducted 2 points; pulse and activity were deducted 1 point respectively). Intensive resuscitative measures even immediate intubations were gave to the premature, at 5 minutes being 10/10. She was limp with tachypnea, groan and face pale. Physical examination showed the widespread hemorrhagic spots, scalp edema and dorsum skin with cyanosis. The liver was palpable $2 \mathrm{~cm}$ below the right midclavicular line costal margin. The spleen was palpable $2.5 \mathrm{~cm}$ below the left midclavicular line costal margin.

Investigations showed hemoglobin level of $10.8 \mathrm{~g} / \mathrm{dl}$ (normal $>14.5 \mathrm{~g} / \mathrm{dl}$ ), the hematocrit value of $17.8 \%$ (normal $>47 \%$ ), blood platelet count of 37,000/cu mm. The mother's ABO blood type is O, and the baby's blood type is A. The elution test and free antibody test were positive. Washed red blood cells $20 \mathrm{ml}$ and a platelet transfusion were given to her. Results of clotting studies shown fibrin level of $0.36 \mathrm{~g} / \mathrm{l}$, lower than normal, with the decreasing blood platelet count and the widespread hemorrhagic spots, disseminated intravascular coagulation (DIC) could be considered. Fresh-frozen cryoprecipitation was given for several days. Biochemistry test showed the albumin $17.89 \mathrm{~g} / \mathrm{l}$ (normal 32 - $48 \mathrm{~g} / \mathrm{l}$ ) and then the albumin was given to lessen the edema. On the second day (20 hours after birth), severe hyperbilirubinemia (total blood bilirubin 199.20 umol/l with the hemoglobin level of $8 \mathrm{~g} / \mathrm{dl}$ ) occurred and was persistent, while the normal level of bilirubin in 24 hours should be less than 102 umol/l. So the baby need another necessitating exchange transfusions with 150 ml washed red blood cell of type $\mathrm{O}, \mathrm{Rh}+$. After the exchange transfusion, hemoglobin increased to $12.2 \mathrm{~g} / \mathrm{dl}$, but the blood platelet level dropped to 26,000/ cu mm; another platelet transfusion was preformed. On the 11th day, blood routine was normal. 
Skull MRI did not see any abnormity.

\section{Disscussion}

Chorioangioma represents a benign neoplasm with proliferation of capillaries and villous stroma associated to multiple gestations, preeclampsia and birth defects in the foetus. This case reports a large tumor (diameter $>5$ $\mathrm{cm}$ ); its incidence rate is about 1/9000-1/3500. The macroscopic, rare lesions are significant to the clinician, because they are associated with a number of pregnancy complications, including polyhydramnios, nonimmune hydrops, fetal heart failure, fetal anemia and thrombocytopenia, fetal growth restriction, preterm delivery, perinatal death, and maternal preeclampsia [2] [3]. Prenatal sonographic usually can see a well-circumscribed, solid masses bulge on the fetal surface or the maternal surface of the placenta [4] [5]. The color Doppler imaging can facilitate the diagnosis if the vessels are identified within the tumor [5]-[7]. Several prenatal interventions had been done and they got variable success rates such as amniodrainage treating polyhydramnios and intrauterine transfusion in proved cases of fetal anemia. Otherwise these therapies are all symptomatic treatment and not the cause of the problem. More aggressive approaches aimed to block vascular supply to the tumor have been developed by several investigators. Nicolini et al. [8] first reported this technique in two pregnancies complicated by polyhydramnios and fetal anemia at 24 and 27 weeks, with good perinatal outcome in both cases.

This case described a rare large chorioangioma in which the very large size of tumor mass led to the well-described maternal complications such as fetal anemia and thrombocytopenia, fetal edema, fetal growth restriction, preterm delivery, and hyperbilirubinemia occurred early. They were closely related with the large vascular tumors by three complicating functions. First, an angiomatous tumor that is characterized by numerous narrow, tortuous, and partially thrombosed vascular networks can easily injure erythrocytes and trap platelets, resulting in a chronic microangiopathic hemolytic anemia and thrombocytopenia of a severe degree. Injured erythrocytes can create much bilirubin and the premature can't metabolize properly, which make the severe hyperbilirubinemia occur just like in this case. Otherwise they act as a physiologic dead space where large amounts of blood can pool in the capillary spaces. If at delivery this blood is not returned to the fetus before cord clamping, severe acute anemia may result, as was seen in the case reported here. Second, the tumor acts as an arteriovenous malformation that shunts large amounts of blood and prevents adequate filling of the fetoplacental vessels in the remaining placenta. Then the venous congestive syndrome increased returned blood volume and raised pulse pressure performed, which can cause severe edema, cardiomegaly, hepatomegaly, and even congestive heart failure. Third the tumor can act as a functional dead space, resulting in a significant portion of the fetal circulating blood being deprived of the oxygenating and metabolizing effects of the normally functioning placenta. This could result in significant fetal malnutrition and perhaps fetal distress [9]. In this case, the premature birth weight is $1940 \mathrm{~g}$ with sever edema, belonging to appropriate for gestational age premature, but she is $38 \mathrm{~cm}$ long, belonging to fetal distress.

This case is of particular interest because the hemolytic process and thrombocytopenia coexisted are severe. The tumor was large and the anemia at birth was also severe. The favorable outcome was most likely influenced by the emergency cesarean section and proactive washed red blood cell, platelet transfusion, even exchange transfusions. It is also significant to the clinician to recognize the chorioangioma and search the methods to treat and prevent the tumor to decrease the mortality.

\section{References}

[1] Wallenburg, H.C.S. (1971) Chorioangioma of the Placenta. Thirteen New Cases and a Review of the Literature from 1939 to 1970 with Special Reference to the Clinical Complications. Obstetrical \& Gynecological Survey, 26, 411-425. http://dx.doi.org/10.1097/00006254-197106000-00001

[2] Fox, H. (1997) Non-trophoblastic Tumours of the Placenta. In: Pathology of the Placenta, 2nd Edition, WB Saunders, London, 354-382.

[3] Benirschke, K. and Kaufmann, P. (2000) Benign Tumors: Chorangiosis. In: Pathology of the Human Placenta, 4th Edition, Springer, New York, 778-789. http://dx.doi.org/10.1007/978-1-4757-4199-5_24

[4] Bromley, B. and Benacerraf, B.R. (1994) Solid Masses on the Fetal Surface of the Placenta: Differential Diagnosis and Clinical Outcome. Journal of Ultrasound in Medicine, 13, 883-886.

[5] Sepulveda, W., Sebire, N.J., Harris, R. and Nyberg, D.A. (2003) The Placenta, Umbilical Cord, and Membranes. In: Nyberg, D.A., McGahan, J.P., Pretorius, D.H., Pilu, G., Eds., Diagnostic Imaging of Fetal Anomalies, Lippincott Wil- 
liams \& Wilkins, Philadelphia, 85-132.

[6] Jauniaux, E. and Ogle, R. (2000) Color Doppler Imaging in the Diagnosis and Management of Chorioangiomas. Ultrasound in Obstetrics \& Gynecology, 15, 463-467. http://dx.doi.org/10.1046/j.1469-0705.2000.00127.x

[7] Sepulveda, W., Aviles, G., Carstens, E., Corral, E. and Perez, N. (2000) Prenatal Diagnosis of Solid Placental Masses: The Value of Color Flow Imaging. Ultrasound in Obstetrics \& Gynecology, 16, 554-558. http://dx.doi.org/10.1046/j.1469-0705.2000.00245.x

[8] Nicolini, U., Zuliani, G., Caravelli, E., Fogliani, R., Poblete, A. and Roberts, A. (1999) Alcohol Injection: A New Method of Treating Placental Chorioangiomas. Lancet, 353, 1674-1675. http://dx.doi.org/10.1016/S0140-6736(99)00781-3

[9] Bauer, C.R., Fojaco, R.M., Bancalari, E., et al. (1978) Microangiopathic Hemolytic Anemia and Thrombocytopenia in a Neonate Associated With a Large Placental Chorioangioma. Pediatrics, 62, 574-577. 